8. Куделин С.Г., Барабанов М.И., Кобрунов А.И. Программный редактор "GeoVIP" как компонент среды физико-геологического моделирования на основе системной инверсии // Информационные технологии в управлении и экономике. - 2012. - №3 (03). - C. 18-26. - URL:

https://elibrary.ru/item.asp?id=26236619 (дата обращения 17.05.2021).

9. Логачев А.А., Захаров В.П. Магниторазведка. - 5-е изд., перераб. и доп. - Л.: Недра, 1979. - 351 с.: ил.

10. 10.Матусевич А.В. Гравиразведка Прикаспийской впадины [Электронное издание]. - Ливны: Издатель Мухаметов Г.В., 2013. - 176 с. - URL:

http://www.academy.kz/images/files/matusevich/gravirazvedka.pdf. (дата обращения 17.05.2021).

11. Немцов Л.Д. Высокоточная гравиразведка. - М.: Недра, 1967. - 230 с.

12. Никитин А.А., Булычев А.А. Комплексный анализ и комплексная интерпретация геофизических полей: учеб. пособие. - М., ВНИИгеосистем, 2015. - 93 с.: ил. - URL: http://geophys.geol.msu.ru/Komplex.pdf (дата обращения 17.05.2021).

13. Программа интерпретации геопотенциальных полей методом векторного сканирования VECTOR: свидетельство об офиц. регистрации № 2004611611 / Новоселицкий В.М., Кутин В.А., Чадаев М.С., Бычков С.Г., Простолупов Г.В., Антипин В.В.; заявитель и правообладатель ГИ УрО РАН. - № 2004610697; заявл. 29.03.04; зарегистрировано 01.07.04.

14. Старостенко В.И. Устойчивые численные методы в задачах гравиметрии. - Киев, Наук. думка, 1978. 227 с.: ил.

15. Шванк О.А., Люстих Е.Н. Интерпретация гравитационных наблюдений: Теория и практика решения прямой и обратной задачи гравиметр. разведки. - М.; Л.: Гостоптехиздат, 1947. - 400 с.: черт.

16. Baatz M., Schape A. Multiresolution Segmentation: An Optimization Approach for High Quality MultiScale Image Segmentation. // Angewandte Geographische Informations-Verarbeitung XII / eds.: Strobl J., Blaschke T., Griesbner G. - Wichmann Verlag, 2000. - 542 p.

17. Hinze W.J., Aiken C., Brozena J., Coakley B., Dater D., Flanagan G., Forsberg R., Hildenbrand T., Keller G.R., Kellogg J., Kucks R., Li X., Mainville A., Moring R., Pilkington M., Plouff D., Ravat D., Roman D., Urrutia-Fucugauchi J., Veronneau M., Webring M., Winester D. New standards for reducing gravity data: the North American gravity database // Geophysics. - 2005. - V. 70, 4. - P. J25-J32. - DOI: $101190 / 1 / 1988183$.

18. Oasis montaj: Программное обеспечение для обработки данных и построения карт. - Geosoft, 2012.

19. Oasis montaj: Software for Earth Science Mapping and Processing. - Geosoft, 2012.

УДК 550.8.05

DOI:10.7242/echo.2021.2.11

\title{
КОЛИЧЕСТВЕННЫЙ АНАЛИЗ ИНТЕРФЕРЕНЦИОННЫХ ЭФФЕКТОВ В ШАХТНОЙ СЕЙСМОРАЗВЕДКЕ
}

\author{
И.А. Санфиров ${ }^{1}$, Т.В. Байбакова ${ }^{1}$, С.А. Миронов ${ }^{2}$ \\ ${ }^{I}$ Горный институт УрО РАН, г. Пермь \\ ${ }^{2}$ ПАО «Уралкалий»
}

\begin{abstract}
Аннотация. Выбран тестовый участок шахтного поля соляного рудника с известными особенностями геологического строения. Выполнены наземные и шахтные сейсморазведочные исследования. Определены особенности волновых полей, обусловленные геологическим строением тестового участка. Реализована «специальная» шахтная сейсморазведочная технология, инициирующая интерференционное волновое поле. Оценены искажения волновых параметров за счет подобных эффектов, влияющие на формирование интерпретационных заключений.
\end{abstract}

Ключевые слова: шахтная сейсморазведка, отраженные волны, интерференционные явления, поперечные волны, продольные волны, интерпретационные искажения.

При интерпретационных построениях по результатам цифровой обработки сейсморазведочных данных необходим учет разного рода интерференционных эффектов, вызванных тонкослоистым строением реальных сред. Вероятность их проявления оценивается по результатам спектрального анализа сейсмических записей, которые, как известно, в частотной области представляют собой произведение ампли- 
тудных спектров среды и исходного сигнала. Подобный подход на основе оценки частотной характеристики среды в теории сейсморазведочных исследований существует еще с прошлого века $[1,2]$. Давно и хорошо известны явления «диструктивной» и «конструктивной» интерференции по результатам картирования зон выклинивания продуктивных пластов [3].

Интерференционные явления могут существенно изменить значения кинематических и динамических характеристик результирующих волновых полей. Так, оценка изменения интенсивности отраженных волн в подобных условиях не позволяет судить об акустической жесткости отражающих границ. Реальное время отражения от конкретной геологической границы «плавает»в пределах интервала осреднения ее акустической характеристики во временном масштабе на базе длины волны. Частотный состав результирующего волнового поля и количественные оценки скоростей распространения упругих волн также могут меняться за счет подобных эффектов.

Сейсмоакустические исследования во внутренних точках среды отличаются повышенным частотным диапазоном относительно наземных, соответственно и возможности интерпретационных заключений выше. При этом актуальность учета искажающих интерференционных явлений в высокочастотной области также возрастает. Для практической оценки возможных последствий интерференционных искажений ряда традиционно интерпретируемых волновых параметров при сейсмоакустических исследованиях в горных выработках поставлен практический эксперимент на одном из соляных рудников Верхнекамского месторождения калийных и магниевых солей.

Выполнено непродольное профилирование по методике общей глубинной точки (МОГТ) в выработках по сильвинитовому пласту АБ (рис. 1), задействованы панельные транспортный и конвейерный штреки.

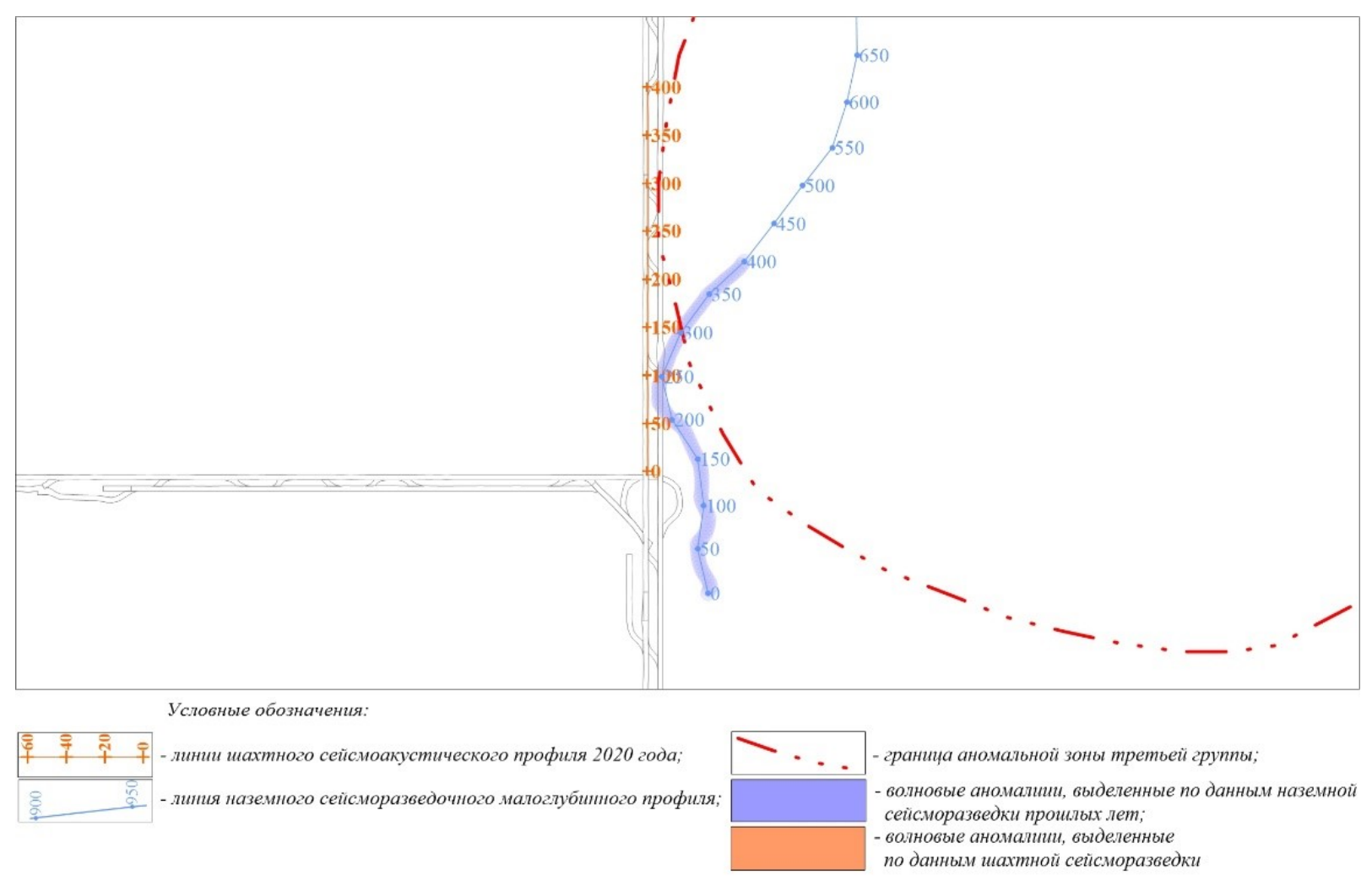

Рис. 1. Обзорная схема района работ 
Шахтный профиль проходит по западной границе аномальной зоны третьей группы, связанной с крупной зоной разубоживания сильвинитовых пластов. Ранее здесь пройден наземный сейсморазведочный профиль и по результатам цифровой обработки и интерпретации выделен участок (700-950м) с осложнениями волнового поля предположительно за счет структурно-литологической изменчивости (рис. 2). Отмечаются типовые волновые признаки зон замещения: повышенный градиент кинематических параметров (рис. 2б) и пониженная интенсивность сейсмической записи (рис. 2в). Совместный эффект от данных изменений волновых параметров представлен на разрезе комплексного параметра (рис. 2г). Выделен ряд отражающих горизонтов, приуроченных к кровле : соляномергельной толщи (СМТ), переходной пачки (ПП), покровной каменной соли (ПКС), карналлитового пласта Е (Ек) и интервалу маркирующей глины (МГ).
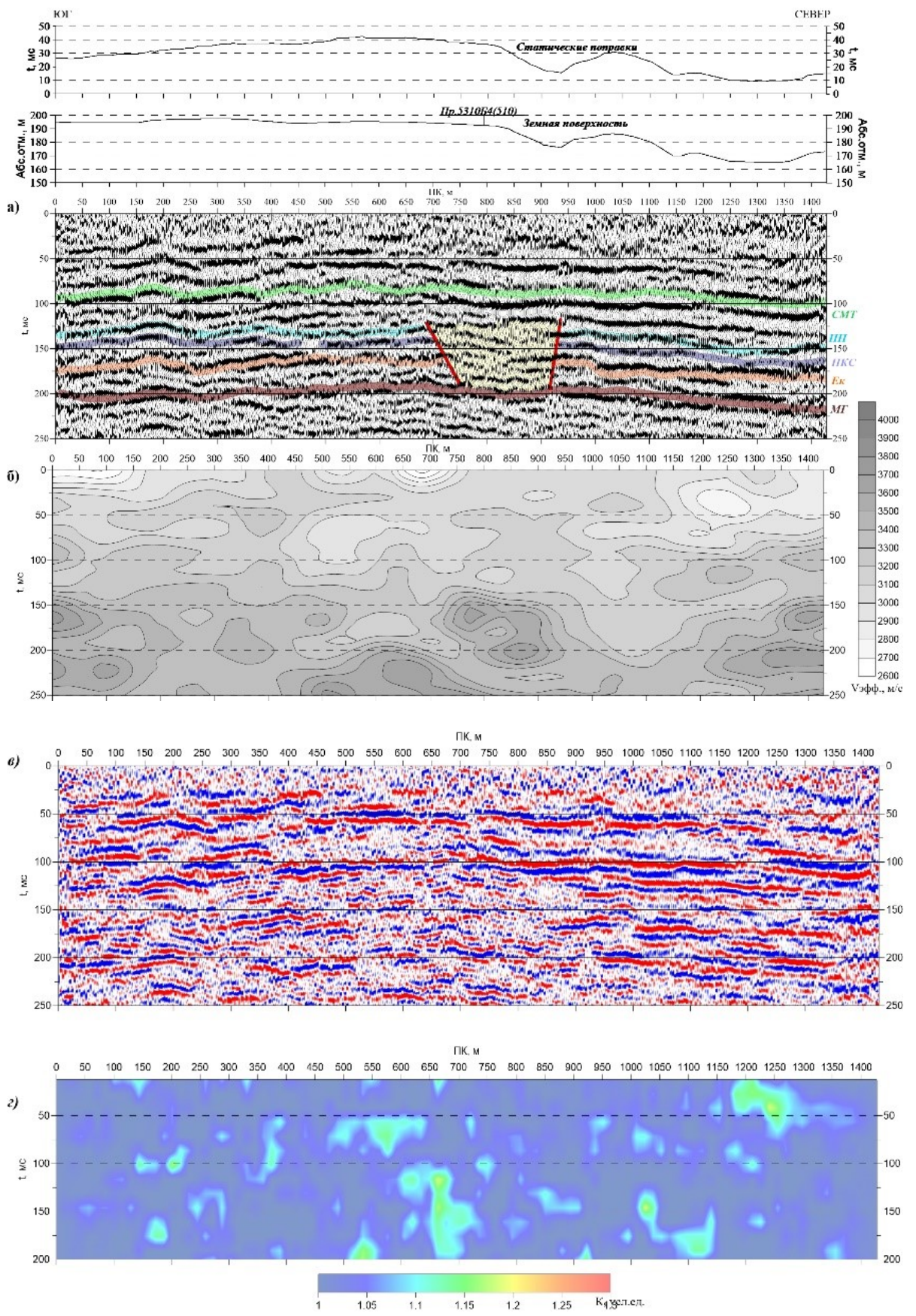

Рис. 2. Результаты цифровой обработки по наземному сейсмическому профилю: а) временной разрез ОГТ, б) скоростная характеристика, в) динамический временной разрез, г) комплексный параметр 
Шахтные сейсморазведочные наблюдения выполнены в двух вариантах полевых технологий:1) традиционная, 2) «специальная». В рамках традиционной [4] пункты приема располагались у западной стены транспортного (западного) штрека, а пункты возбуждения - по кровле у западной стены конвейерного (восточного) штрека.

При реализации «специальной», предназначенной для инициирования интерференционных эффектов, сейсмоприёмники располагались горизонтально в западной стене, в 1 метре над почвой, а пункты возбуждения в эту же стену на разных уровнях. Нижняя линия возбуждения проходила в 15-20 см под сейсмоприёмниками, а верхняя - на 1,5 м выше нижней.

Содержание «специальной» технологии основывается на представлениях о характеристике направленности точечного ударного источника упругих волн [5] и результатах ранее проведенных экспериментов [6]. Доказан факт интерференционного наложения волн поперечного типа, отраженных от геологических границ верхнего и нижнего полупространств. Для нейтрализации интерференционных эффектов в [7] предлагается разноуровенное возбуждение упругих волн в горизонтальном направлении. Цель подобного методического решения - разделение синхронной регистрации отраженных волн поперечного типа горизонтальной поляризации (SH) из верхнего и нижнего полупространств.

В обоих случаях применяется 64-канальная переменная ассиметричная система регистрации. В начале профиля она реализуется в виде фланговой и затем постепенно «раскрывается» до ассиметричной (рис. 3).

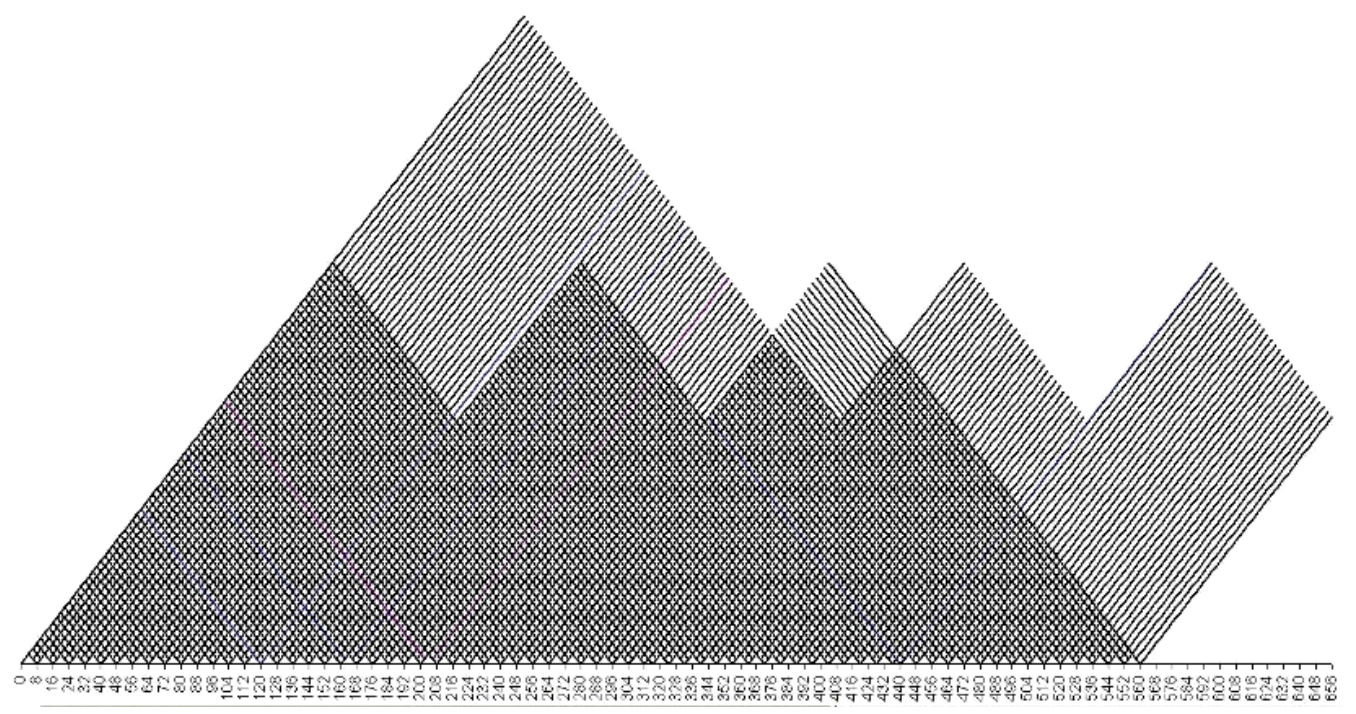

Рис. 3. Система наблюдений на обобщенной плоскости

Параметры системы наблюдений:

- минимальное удаление ПВ от ППк (Xmin) - 0 м;

- $\quad$ максимальное удаление ПВ от ППк (Xmax) -126 м;

- расстояние между ПВ $\left(\Delta \mathrm{X}_{\Pi \mathrm{B})}-2 \mathrm{~m}\right.$; расстояние между ППк $\left(\Delta \mathrm{X}_{\Pi \Pi)}-2 \mathrm{M}\right.$;

- количество активных каналов $(\mathrm{N})-64$;

- номинальная кратность наблюдений (n) - 32 .

Результаты цифровой обработки и интерпретации шахтных сейсмоакустических данных, полученных в рамках традиционной технологии при изучении упругих волн продольного типа (Р), представлены на рис. 4. Основные отражающие горизонты при- 
урочены к кровлям пластов: Г (ОГ Гк), Е (ОГ Ек), И (ОГ Ик), ПКС (ОГ ПКСк), ПП (ОГ ППк). К подошве покровной каменной соли - ОГ ПКСп. Отражающий горизонт «Гипс» приурочен к пласту гипсов в СМТ.
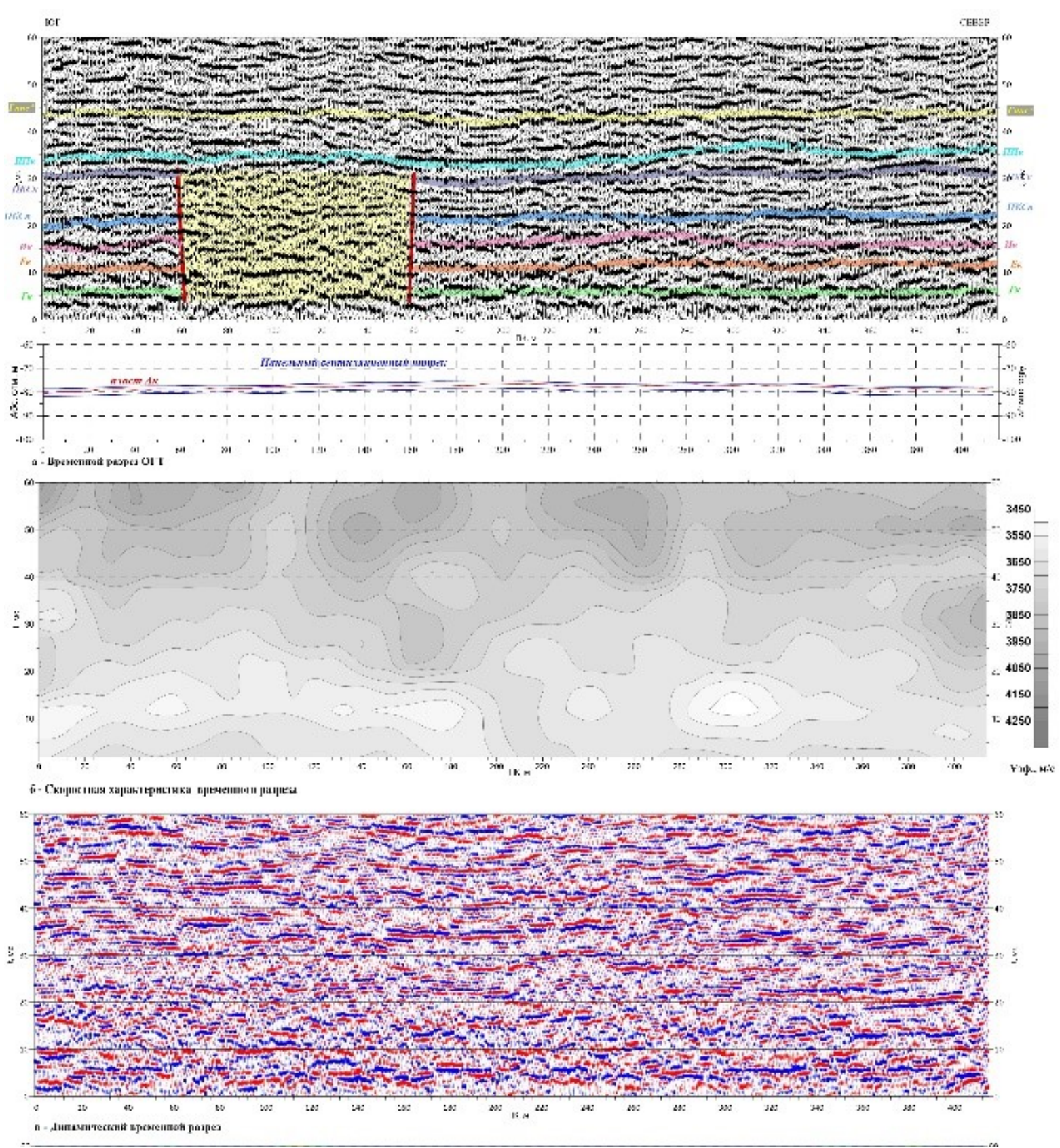

Рис. 4. Результаты цифровой обработки по шахтному сейсмическому профилю (Р-волны): a) временной разрез ОГТ, б) скоростная характеристика, в) динамический временной разрез

Выделяется участок временного разреза пк.60-160м в интервале ОГ Г-ПКСк, судя по характеру изменения составляющих волнового поля связанный с литологической изменчивостью. Отмечается повышенный градиент кинематических параметров (рис. 4б) и пониженные значения динамических (рис. 4в) параметров без значимого нарушения структурных (рис. 4а). Признаки, аналогичные отмеченным ранее на наземном сейсморазведочном профиле.

Шахтные сейсморазведочные данные в соответствии с рекомендациями, представленными в [4], обработаны с целью выделения поперечных волн (SV) вертикальной по- 
ляризации (рис. 5). Участок с аналогичными осложнениями волнового поля в начальной части профиля проявляется и здесь.
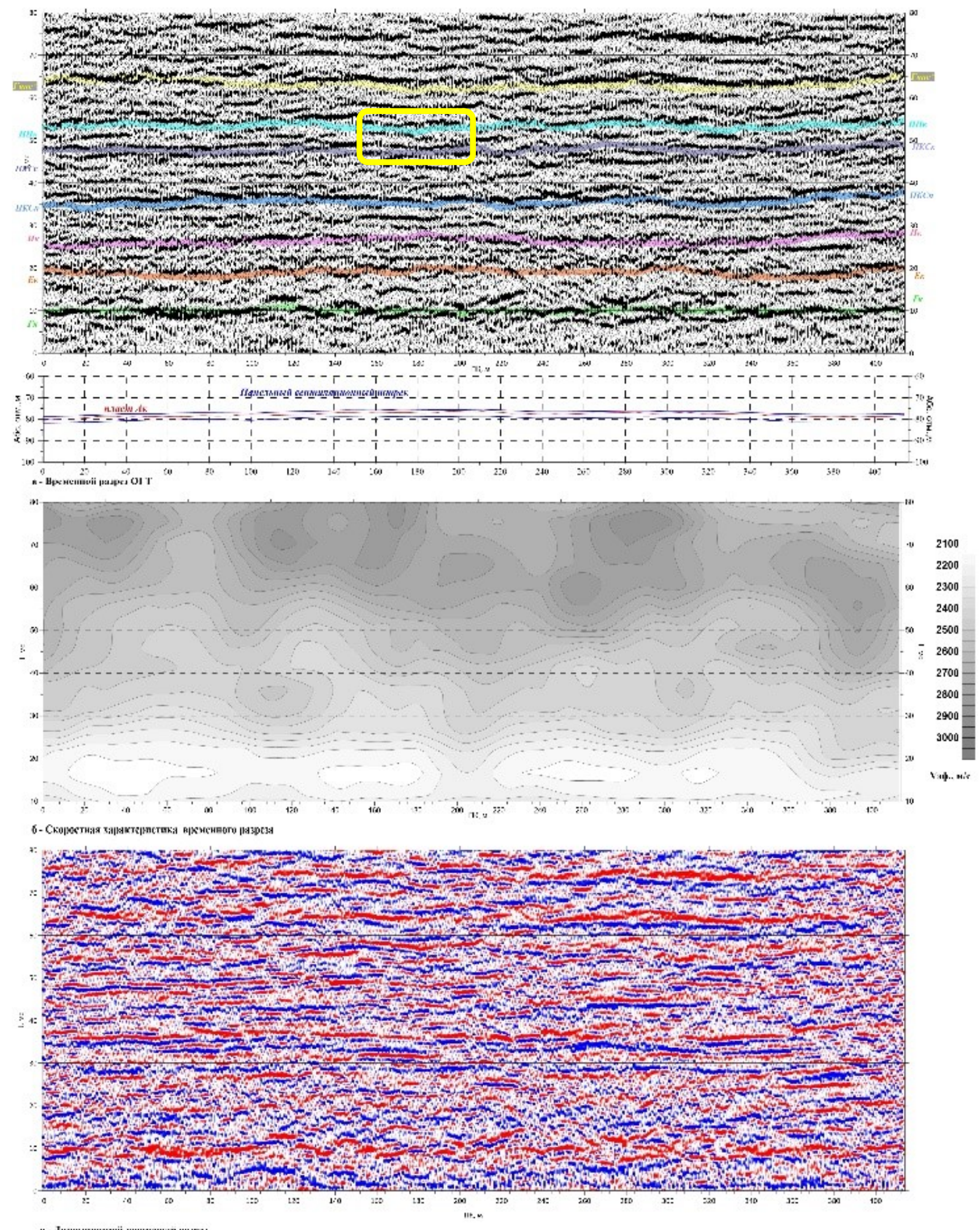

Рис. 5. Результаты цифровой обработки по шахтному сейсмическому профилю (S-волны): a) временной разрез ОГТ, б) скоростная характеристика, в) динамический временной разрез

Таким образом, по результатам комплексной интерпретации данных наземных и шахтных сейсморазведочных исследований прогнозируется литологическая изменчи- 
вость пород продуктивных отложений, подтвержденная результатами бурения, по которым намечены границы геологической аномалии. В пределах данной аномалии карналлитовая толща в разной степени замещена сильвинитами. Следует отметить также, что здесь по результатам бурения установлены близкие удаления от линии наблюдений литологических границ, связанных с контрастными отражающими горизонтами из верхнего (ПКС) и нижнего (МГ) полупространств.

Обработка сейсморазведочных данных, полученных в рамках «специальной» полевой технологии, выполнялась в том же графе, что и для выделения P и SV волн. Следует отметить, что на результатах обработки как для как верхней линии возбуждения (рис. 6а), так и для нижней (рис. 6б) не выделяется ранее отмеченного осложнения волнового поля, обусловленного литолого-фациальной изменчивостью продуктивной толщи, установленной по результатам бурения. В качестве причины следует предположить возможность искажения волнового поля интерференционными явлениями при реализации «специальной» технологии за счет переотраженных волн из противоположных плоскостей вследствие специфической характеристики направленности SH волн.
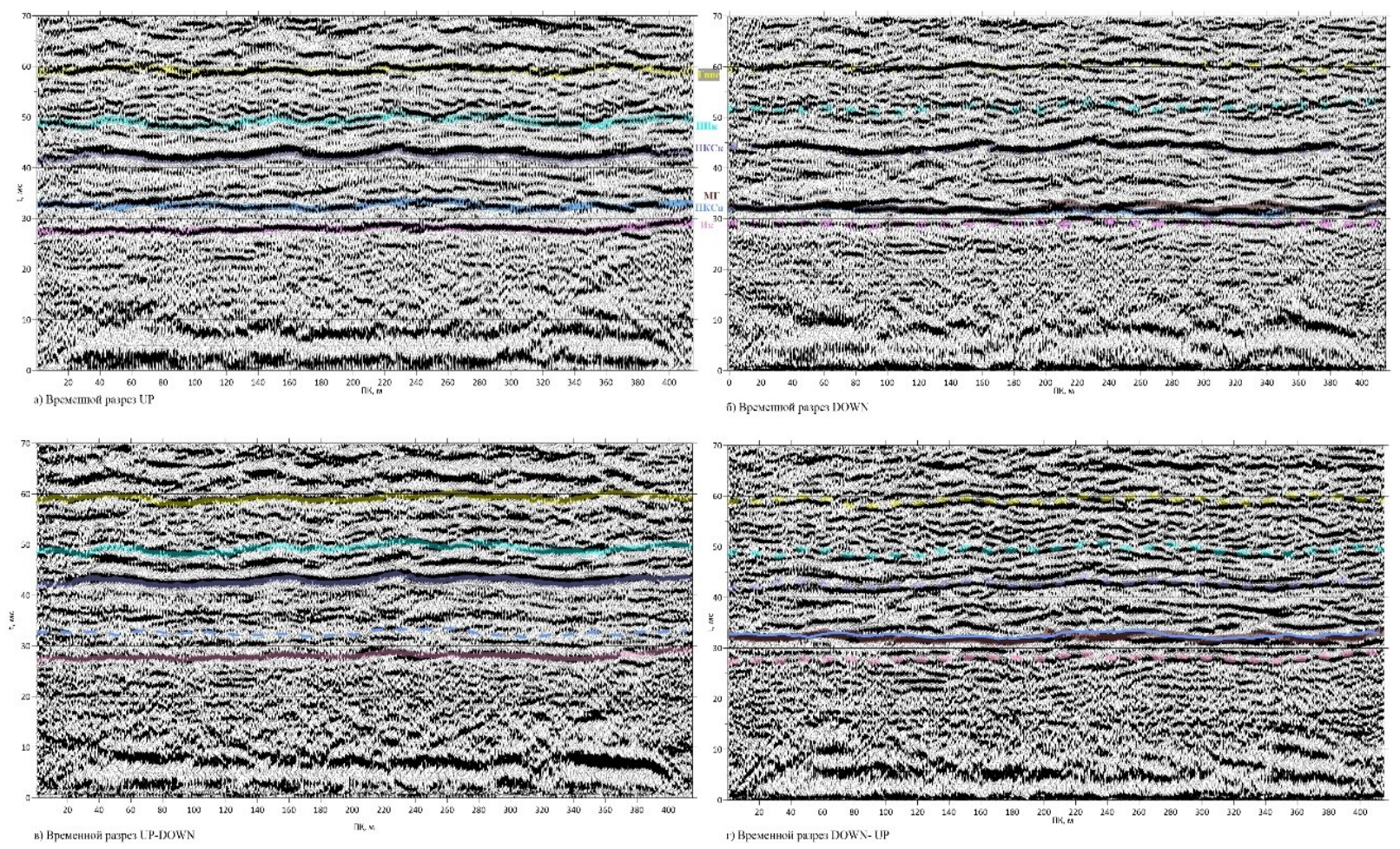

Рис. 6. Результаты цифровой обработки интерференционных волновых полей:

a) верхняя линия возбуждения упругих колебаний, б) нижняя линия упругих колебаний,

в) результат разделения волновых полей для верхнего полупространства,

г) результат разделения волновых полей для нижнего полупространства

Далее, согласно представленным в [7] описаниям, проведем ряд манипуляций, предположительно направленных на подавление интерференционных искажений волнового поля за счет синхронной регистрации отраженных волн сверху и снизу.

1. На временных разрезах, полученных при различных линиях возбуждения (рис. 6а, 6б) выбираем наиболее выраженные оси синфазности с ориентацией на интерпретационную модель (рис. 5д) и выполняем стратиграфическую привязку согласно скоростному закону (0-30 мс-2400 м/с, 60 мс-2600 м/с) как для верхнего, так и нижнего полупространства. 
2. Определяем времена выбранных осей синфазности для их идентификации на основании сравнения временных разрезов, полученных с разными линиями возбуждения (UP, DOWN). Отражающие горизонты с меньшими временами должны соответствовать плоскости с ближайшей линией возбуждения (верхняя плоскость - верхняя линия, нижняя плоскость - нижняя линия). Определяем их параметры: амплитуды, сигнал\помеха, частота.

3. Выполняем разделение волнового поля по схеме из [7]:

- временной разрез для верхнего полупространства(«верх», рис. 6в) = разности волнового поля при верхней линии возбуждения (UP) и волнового поля при нижней линии возбуждения (DOWN) с положительным временным сдвигом на 6 дискрет $(0.6$ мс $=1.5$ M/2400 м/c) - UP-DOWN;

- временной разрез для нижнего полупространства («низ», рис. 6г) = разности волнового поля при нижней линии возбуждения (DOWN) и волнового поля при верхней линии возбуждения (UP) с положительным временным сдвигом на 6 дискрет $(0.6$ мс $=$ $1.5 \mathrm{M} / 2400 \mathrm{M} / \mathrm{c})$ - DOWN-UP;

4. Определяем параметры волнового поля на временах ранее идентифицированных по п. 2 отражающих горизонтов: амплитуды, сигнал\помеха, частота.

Очевидно, что при подавлении интерференционных эффектов за счет регистрации на близких или идентичных временах волн, отраженных сверху и снизу, параметры отражающих горизонтов, идентифицированных для верхней плоскости на суммарном волновом поле «ир», должны быть идентичны полученным на разрезе «верх» и соответственно параметры отражающих границ на разрезе «down» должны быть идентичны полученным на разрезе «низ». Кроме того, должны проявиться и известные особенности геологического строения, отмеченные по результатам наземной сейсморазведки и выявленные в суммарных полях $\mathrm{P}$ и $\mathrm{SV}$ волн, зарегистрированных в рамках традиционной шахтной сейсморазведочной технологии.

Как следует из сопоставления волновых картин, представленных на рис. 5, рис. 6в и рис. 6г, контрольная особенность волнового поля, обусловленная геологическим строением, не проявляется и после рассмотренных выше операций, предположительно направленных на разделение волновых полей. На результатах разделения волновых полей, хотя динамически более выражены отражения из целевого полупространства, «рудименты» из нецелевого также остаются значимы. Они проявляются дополнительно, как ПКСк на разрезе «вниз», либо просто интерферируют с целевыми. В данном случае таковыми являются ОГ ПКСп (верх) и МГ (вниз). Это обусловлено одинаковым расстоянием отражающих границ от линии наблюдений, согласно геологоразведочным данным.

На рис. 7 представлены графики параметров результирующего волнового поля, полученных для разрезов UP - «верх», и DOWN - «низ». Из анализа представленных результатов очевидно наличие существенных различий одноименных участков волнового поля как для нижней плоскости, так и для верхней.

Максимальные разнонаправленные отклонения более $100 \%$ отмечаются для параметра сигнал/помеха, определяющего регулярность отражающего горизонта, далее на $80 \%$ могут отличаться амплитуды и до $20 \%$ - частоты. В целом более значимые отклонения отмечаются для отражающих горизонтов, отнесенных к верхней плоскости, что объясняется ее существенно более тонкослоистым разрезом относительно нижней.

Следовательно, влияние интерференционных эффектов не исключено и на предположительно разделенных волновых полях, а столь значимые искажения сейсморазведочных параметров могут повлиять на итоговое интерпретационное заключение. Оче- 
видно, что при проведении шахтных сейсморазведочных исследований следует избегать искусственного создания дополнительных возможностей проявления интерференционных эффектов влияющих на формирование интерпретационных заключений, чтобы потом искать пути борьбы с ними.
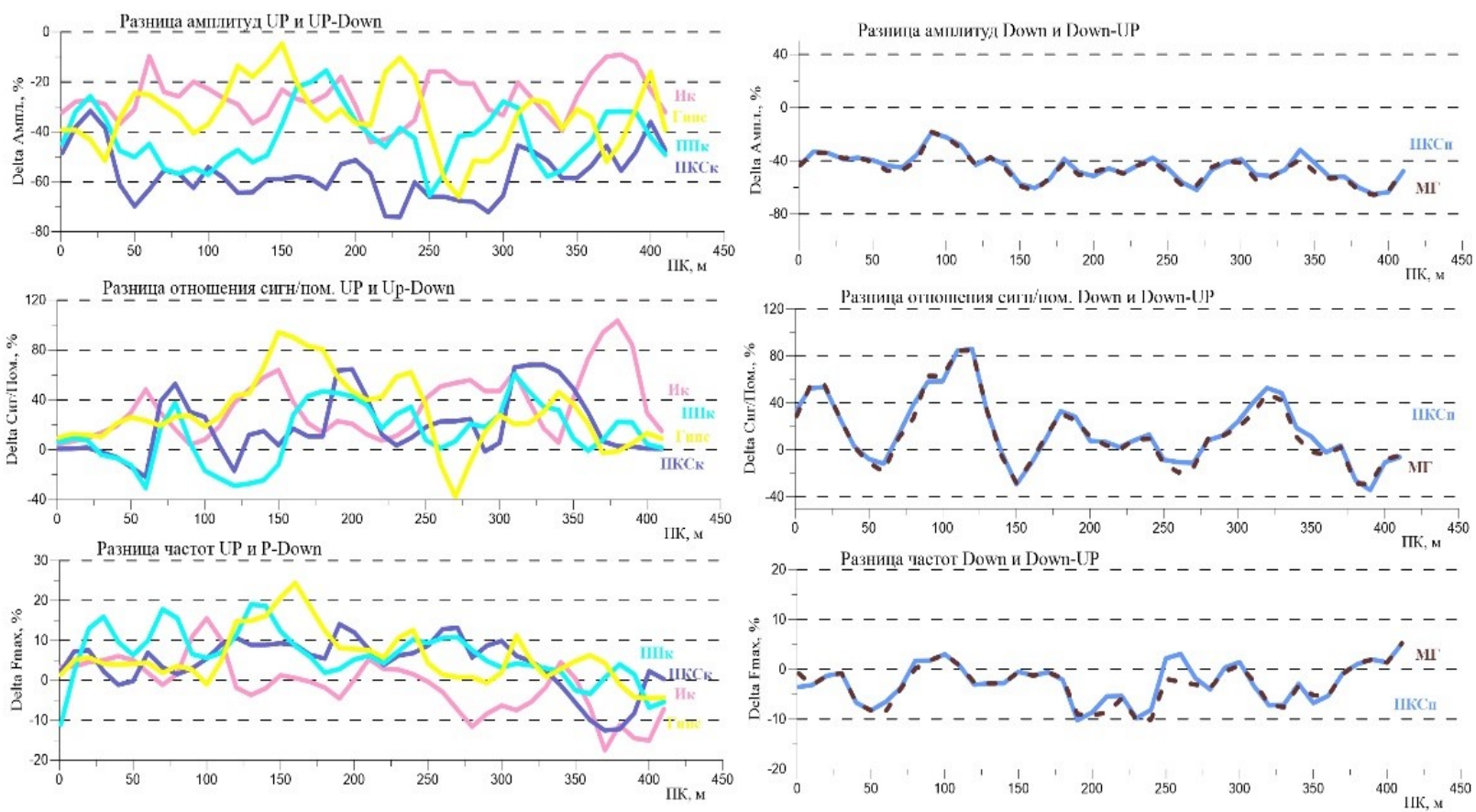

Рис. 7. Сопоставление параметров целевых отражающих горизонтов

Работа выполнена по теме ГР № АААA-A18-118040690028-5.

\section{БИБЛИОГРАФИЧЕСКИЙ СПИСОК}

1. Бяков Ю.А., Лихачев А.А. К спектральному выделению сейсмических границ // Геофизические изыскания. - Пермь, 1975. - С. 161-164.

2. Shoenberger M., Levin F.K. Reflected and transmitted filter functions for simple subsurface geometries // Geophysics. - 1976. - V. 41, № 6. - P. 1305-1317. - DOI: 10.1190/1.1440681.

3. Санфиров И.А., Ильичев Ю.В. Результаты изучения зоны выклинивания продуктивных отложений способами динамического анализа // Разведочная геофизика: отечеств. производств. опыт: экспрессинформ. / ВИЭМС. - М., 1988. - вып. 6. - С. 14-20.

4. Бабкин, А.И., Санфиров И.А. Практические примеры решения горнотехнических задач методами шахтной сейсмоакустики // Горный информационно-аналитический бюллетень (научно-технический журнал). - 2011 - № 4. - С. 152-159.

5. Никитин В.Н. Основы инженерной сейсмики. - М.: Изд-во МГУ, 1981. - 176 с.: ил.

6. Бабкин А.И. Информационные возможности шахтной сейсмоакустики за счет направленности источника упругих колебаний // Стратегия и процессы освоения георесурсов: материалы ежегод. науч. сес. ГИ УрО РАН по результатам НИР в 2008 г. - Пермь, 2009. - С. 171-173.

7. Жуков А.А., Пригара А.М., Царев Р.И., Шусткина И.Ю. Способ шахтной сейсморазведки для изучения особенностей геологического строения ВКМС // Горный информационно-аналитический бюллетень (научно-технический журнал). - 2019. - № 4. - С. 121-136. - DOI: 10.25018/0236-1493-2019-040-121-136. 